\title{
The significance of systematic lymph node dissection in surgery for early-stage non-small cell lung cancer patients aged $\leq 40$ years
}

\author{
Zhi-Yi Guo $^{\#}$, Jiang-Hao Ren", Yuan-Yuan Xu, Rui-Jun Liu, Hui Tao, Jia Huang, Qiang Tan \\ Shanghai Lung Cancer Center, Shanghai Chest Hospital Affiliated to Shanghai Jiao Tong University, Shanghai, China \\ Contributions: (I) Conception and design: ZY Guo, JH Ren; (II) Administrative support: Q Tan, J Huang; (III) Provision of study materials or patients: \\ RJ Liu, H Tao; (IV) Collection and assembly of data: ZY Guo, YY Xu; (V) Data analysis and interpretation: Q Tan, J Huang; (VI) Manuscript \\ writing: All authors; (VII) Final approval of manuscript: All authors. \\ \#These authors contributed equally to this work as first authors. \\ Correspondence to: Dr. Qiang Tan, MD; Dr. Jia Huang, MD. Shanghai Lung Cancer Center, Shanghai Chest Hospital Affiliated to Shanghai Jiao Tong \\ University (SJTU), Shanghai 200030, China. Email: dr_tanqiang@sina.cn; huangjiadragon@126.com.
}

Background: Surgery remains the best option for treating early-stage non-small cell lung cancer (NSCLC), and lymph node dissection (LND) is an important step in this approach. However, the extent of LND in the general age population, especially in young patients, is controversial. This retrospective study aimed to investigate the correlation between systematic lymph node dissection (SLND) and prognosis in young ( $\leq 40$ years) patients with stage IA NSCLC.

Methods: Clinicopathological data of 191 patients aged $\leq 40$ years who underwent surgical pulmonary resection for stage IA NSCLC between January 2010 and December 2016 were retrospectively collected. Of the patients, 104 received SLND (SLND group), while the other 87 patients underwent sampling or no LND (non-SLND group). The disease-free survival (DFS) and overall survival (OS) curves of the patients from each group were plotted using the Kaplan-Meier method, and the correlations of the patients' clinical factors with prognosis were also analyzed.

Results: The median follow-up period was 55 months. During follow-up, 7 patients died, and recurrence or metastasis was detected in 16 patients. Kaplan-Meier analysis revealed no difference in DFS $(\mathrm{P}=0.132)$ between the SLND and non-SLND group, but a significant difference was found between the groups in OS $(\mathrm{P}=0.022)$. Additionally, there was no statistically pronounced difference in OS or DFS between male and female patients. Multivariate survival analysis showed that the type of SLND, as well as tumor size, is an independent prognostic factor for DFS (HR, 3.530; 95\% CI, 1.120-11.119; P=0.031) and OS (HR, 13.076; 95\% CI, 1.209-141.443; P=0.034).

Conclusions: For young (age $\leq 40$ ) stage IA NSCLC patients with pathological invasive adenocarcinoma, intraoperative SLND can improve the DFS and OS. Further studies are needed to verify the most optimal degree of LND in young patients.

Keywords: Early-stage non-small cell lung cancer (early-stage NSCLC); lymph node dissection; young patients; prognosis

Submitted Jan 11, 2021. Accepted for publication Feb 10, 2021.

doi: $10.21037 /$ jtd-21-190

View this article at: http://dx.doi.org/10.21037/jtd-21-190

\footnotetext{
^ ORCID: 0000-0002-1865-0592.
} 


\section{Introduction}

For more than a decade, lung cancer has had the highest global morbidity and mortality rates of any malignancy (1). With the increasing application of lung cancer screening and improvement of screening techniques, a larger number of young lung cancer patients are being diagnosed and treated at an early stage $(2,3)$. A diagnosis of lung cancer can have a massive impact on young people and their families. Not only are young people expected to have a long time left to live, but they often make a significant contribution to the economy and play important roles in caring for their families (4). Therefore, improving the survival time of young lung cancer patients is crucial.

With the widespread use of CT screening in recent years, the proportion of young lung cancer patients given a diagnosis at an early stage has risen significantly, and in most cases, the postoperative pathology is non-small cell lung cancer (NSCLC) $(5,6)$. Surgery is the best treatment option for early-stage NSCLC, and includes lymph node dissection (LND) as an important step $(7,8)$. However, the extent of lymph node clearance remains controversial. Previous studies have shown that accurate lymph node staging is an important prognostic factor in patients undergoing surgery (9). It is generally accepted that systematic lymph node dissection (SLND) during surgery not only provides more accurate lymph node pathological staging than sampling or no LND, but it can also eradicate involved or occult metastatic lymph nodes, thus significantly improving the prognosis of the patient $(10,11)$. However, an influential randomized clinical trial demonstrated that compared with systematic lymph node sampling, extensive SLND failed to improve the disease-free survival (DFS) or overall survival (OS) of NSCLC patients without mediastinal or hilar lymph node involvement (12). Furthermore, the standard management of lymph nodes recommended by the National Comprehensive Cancer Network (NCCN) guidelines does not specifically distinguish between mediastinal LND or systematic lymph node sampling during lobectomy, nor is the age range for treatment specified (13).

Therefore, the current study aimed to investigate the correlation between SLND and prognosis in young ( $\leq 40$ years) patients with stage IA NSCLC.

We present the following article in accordance with the STROBE reporting checklist (available at http://dx.doi. org/10.21037/jtd-21-190).

\section{Methods}

\section{Study design and patients}

The study was conducted in accordance with the Declaration of Helsinki (as revised in 2013). The study was approved by the institutional ethics board of Shanghai Chest Hospital [No. KS(Y)1744], and individual consent for this retrospective analysis was waived. The clinicopathological data of 2,303 patients aged $\leq 40$ years who, between January 2010 and December 2016, underwent lobectomy or sublobectomy with curative intent for stage IA NSCLC in Shanghai Chest Hospital, China, were retrospectively analyzed (Figure 1).

The inclusion criteria included: (I) aged $\leq 40$ years; (II) NSCLC of pathologic stage IA (pT1N0M0); and (III) histologic type was invasive adenocarcinoma. Patients meeting any of the following criteria were excluded from the study: (I) received adjuvant therapy before or after surgery; (II) multiple primary pulmonary tumors; (III) incomplete medical records or follow-up data; (IV) a history of other malignant tumors.

By conducting a search of the medical record database of our institution, we collected and classified the data from the clinical records of all eligible patients, including sex, age, circulating tumor markers, operative procedure, surgical technique, lesion site, adenocarcinoma subtype, type of LND (SLND or non-SLND). For uniform tumor staging, we converted tumor stage defined by the $6^{\text {th }}$ or $7^{\text {th }}$ edition TNM classifications to the appropriate American Joint Committee on Cancer (AJCC) $8^{\text {th }}$ edition stage (14).

Patients were followed up to 26 May, 2020, or the date of death, mainly by telephone or home visit. The primary endpoint was OS, which was calculated as the time interval from the date of surgery until the date of death from a lung cancer-related cause or 26 May, 2020. DFS served as the secondary endpoint and was defined as the time interval from the date of surgery to the date of first relapse. Both DFS and OS were calculated in months.

The preoperative circulatory tumor markers carcinoembryonic antigen (CEA) and cytokeratin 19 fragment antigen (CYFRA21-1), which are associated with lung adenocarcinoma, are routinely tested in our hospital before surgery. We divided the patients' test results into 3 categories: absence of test, exceeding the standard, and normal. Operative procedures included lobectomy 


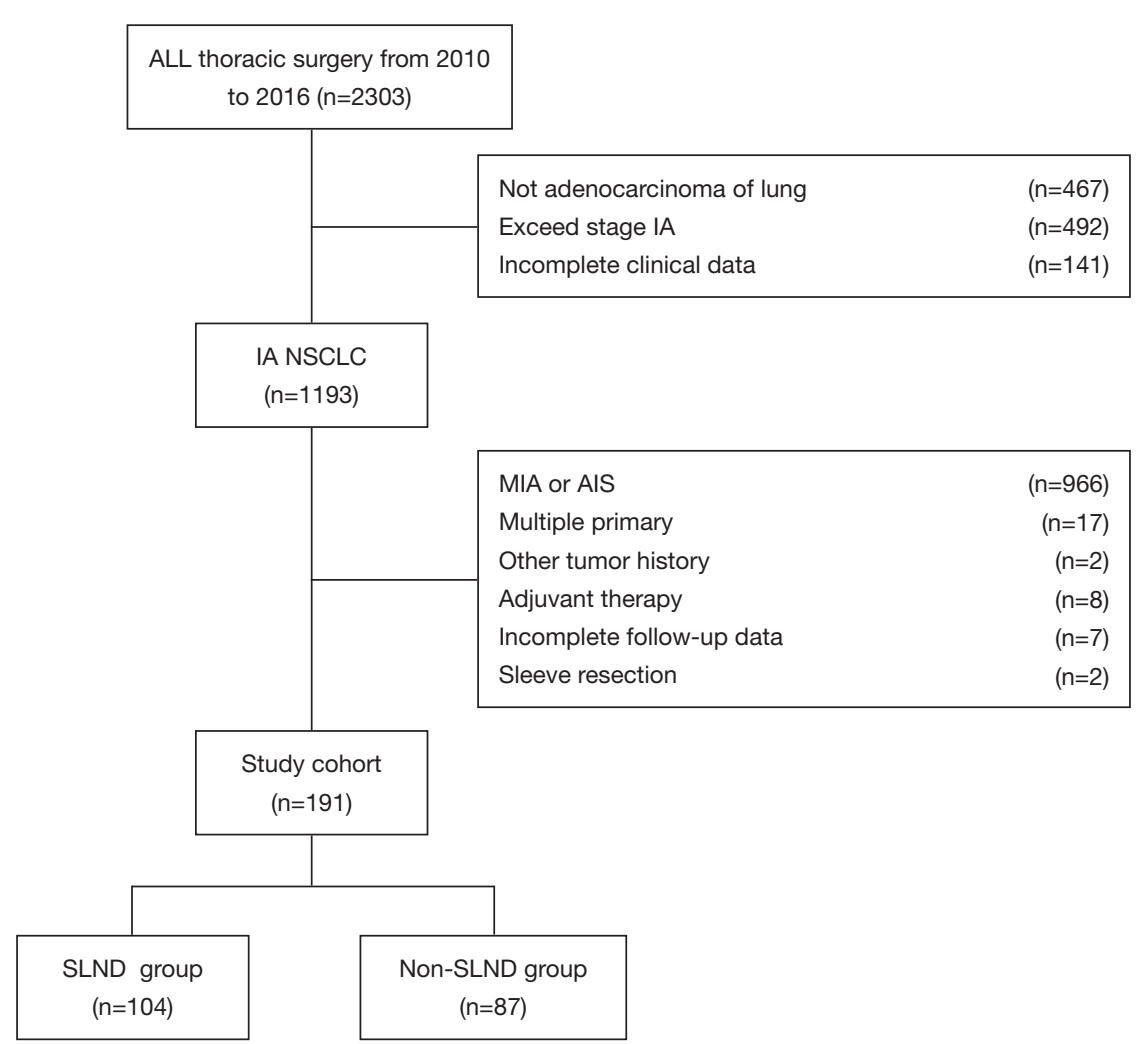

Figure 1 Study inclusion flowchart. MIA, minimally invasive adenocarcinoma; AIS, adenocarcinoma in situ; NSCLC, non-small cell lung cancer; SLND, systematic lymph node dissection.

and sublobectomy (segmentectomy or wedge resection). Surgical techniques include video-assisted thoracoscopic surgery (VATS) and thoracotomy, with the Da Vinci robotassisted thoracoscopic surgery (RATS) included within the scope of VATS.

Subtypes of adenocarcinoma were classified according to the World Health Organization's 2004 classification and the latest International Association for the Study of Lung Cancer (IASLC)/American Thoracic Society/European Respiratory Society (15). The dominant subtypes were classified as the more dangerous subtypes, reported in previous studies to have high rates of recurrence (including solid, papillary, and micropapillary adenocarcinomas), and other subtypes (such as acinar, lepidic, large-cell secretory, and fetal adenocarcinomas) $(16,17)$. According to the definition of systematic nodal dissection recommended by the European Society of Thoracic Surgeons (ESTS), at least 3 mediastinal lymph node stations, always including station 7 (subcarinal area), station (hilar lymph nodes) 10 and 11(interlobular lymph nodes), should be systematically dissected (18).

\section{Statistical analysis}

The included patients were divided into the SLND group and the non-SLND group according to whether SLND was performed or not. SPSS (Chicago, IL, USA; version 22.0) was used for data analysis. The Chi-squared test was used to test the distribution differences among groups. The Kaplan-Meier method was used to estimate the influence of various factors on DFS and OS, and the log-rank method was employed to test the results. Factors with $\mathrm{P}<0.1$ and those clinically considered to have an impact on prognosis were included in the Cox regression model for multivariate survival analysis. $\mathrm{P} \leq 0.05$ indicated statistical significance.

\section{Results}

\section{Patient characteristics}

A total of 191 patients who met the criteria were finally included in the analysis. Of them, 104 patients (54.4\%) received SLND, while the remaining 87 patients (45.6\%) underwent sampling or no LND. No statistically significant 
Table 1 Patient clinicopathological characteristics

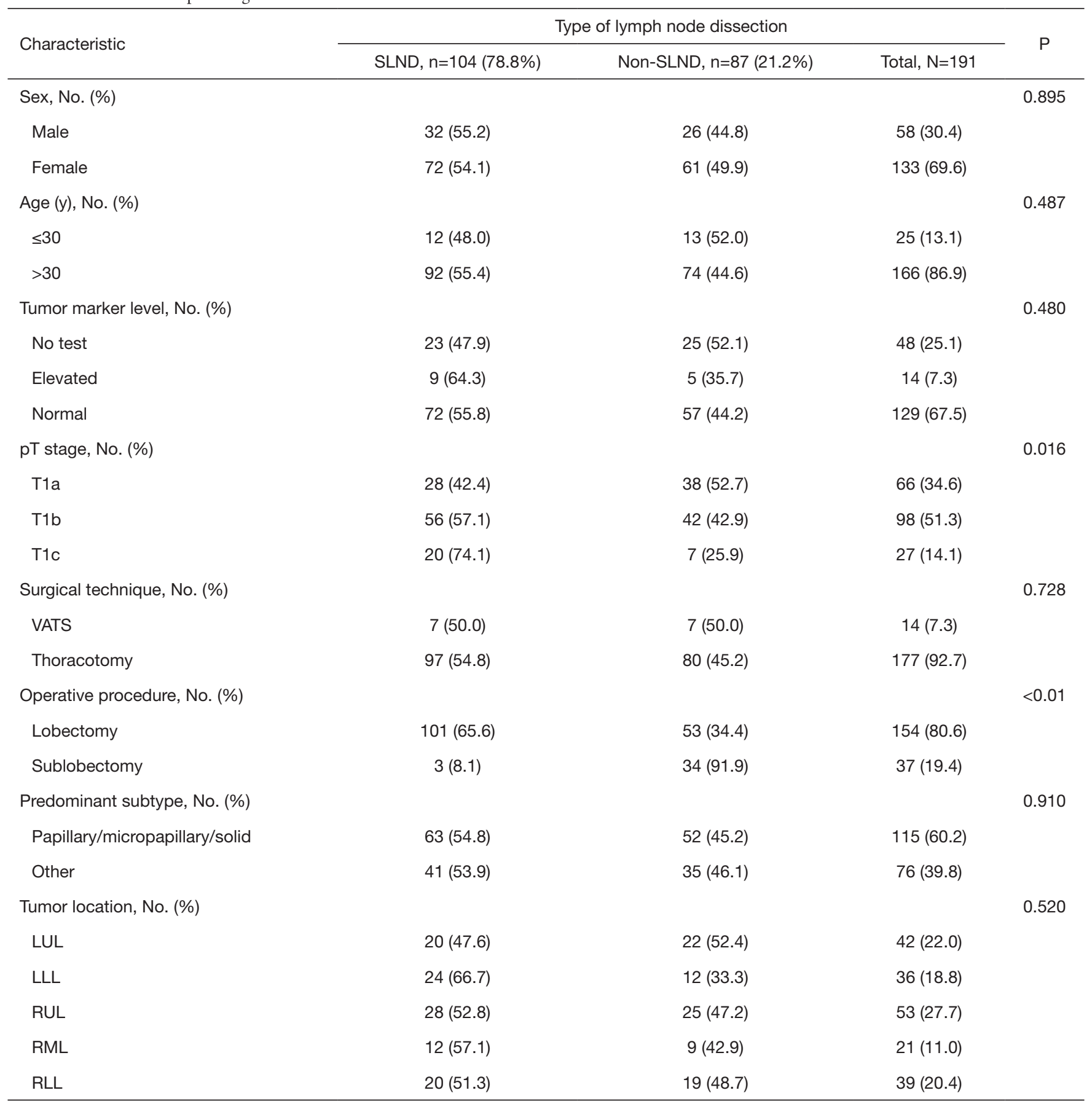

SLND, systematic lymph node dissection; VATS, video-assisted thoracoscopic surgery; LUL, left upper lobe; LLL, left lower lobe; RUL, right upper lobe; RML, right middle lobe; RLL, right lower lobe.

differences were found between the SLND group and the non- SLND group in relation to sex, age, circulating tumor markers, surgical technique, dominant adenocarcinoma subtype, or tumor site (Table 1). The patients in our cohort had a median age of 36 years, and $13 \%(n=25)$ of patients were aged $\leq 30$ years, with the youngest being 11 years old. Females accounted for a larger proportion $(69.9 \%)$ of the included patients. Of the 133 patients who underwent 


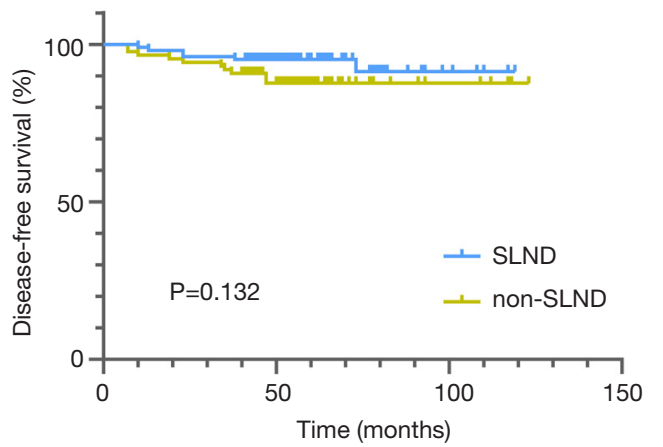

Figure 2 Kaplan-Meier curves of disease-free survival estimates for patients with different types of lymph node dissection. SLND, systematic lymph node dissection.

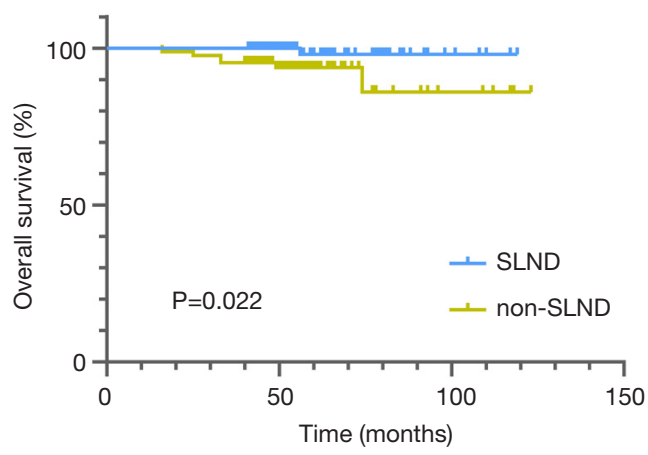

Figure 3 Kaplan-Meier curves of overall survival estimates for patients with different types of lymph node dissection. SLND, systematic lymph node dissection.

preoperative detection of circulating tumor markers, only 14 patients (9.79\%) showed elevated marker levels; therefore, in more than $90 \%$ of these cases, preoperative circulatory tumor markers did not reflect the occurrence of early NSCLC. In terms of surgical technique, more than $90 \%$ of patients underwent VATS.

Furthermore, among these young patients with stage IA non-small cell lung adenocarcinoma, lesions were most frequently found in the right upper lobe $(27.7 \%)$ and occurred least often in the right middle lobe (11.0\%). Acinar adenocarcinoma was the predominant histologic subtype $(44.5 \%)$, and the majority of patients in the entire cohort (80.6\%) underwent lobectomy. Patients who had lobectomy ( $\mathrm{n}=154)$ were more likely to receive SLND than those who had sublobectomy $(\mathrm{P}<0.01)$, with only 3 ( 2 cases of segmental resection and 1 case of wedge resection) of the 37 patients who had sublobectomy receiving SLND.
Furthermore, the median size of the overall tumors was $13 \mathrm{~mm}$, and SLND was more likely to be performed in patients with a lager tumor $(\mathrm{P}=0.016)$.

\section{Survival analysis}

The median follow-up period was 55 months. During follow-up, 7 patients died and 16 patients developed recurrence or metastasis. The Kaplan-Meier analysis revealed no difference in DFS $(\mathrm{P}=0.132)$ between the SLND and non-SLND groups (Figure 2), but a significant difference was found between the groups in OS $(\mathrm{P}=0.022)$ (Figure 3). The 5-year OS rate of the SLND group was superior to that of the non-SLND group $(98.1 \% v s$. 93.8\%). In terms of different tumor diameters, a significant difference was found in DFS but not in OS $(\mathrm{P}=0.005$ and $\mathrm{P}=0.074$, respectively). Additionally, no statistically pronounced differences were found in OS or DFS in relation to sex, circulating tumor markers, surgical technique, operative procedure, dominant pathological type, or tumor site (Table 2, K-M). The multivariate survival analysis showed that type of SLND, along with tumor size, was an independent prognostic factor for both DFS (HR, 3.530; 95\% CI, 1.120-11.119; $\mathrm{P}=0.031$ ) and OS (HR, 13.076; 95\% CI, 1.209-141.443; $\mathrm{P}=0.034$ ) (Table 3, Cox).

\section{Discussion}

This study analyzed the data of 191 patients aged $\leq 40$ years with stage IA NSCLC whose pathological pattern was invasive adenocarcinoma. The results showed that patients who underwent SLND had a better prognosis than those who did not. However, there was no significant difference in prognosis between sublobectomy and lobectomy.

The NCCN guidelines do not strictly specify the treatment of stage IA NSCLC according to age, and lobectomy with SLND is currently the preferred radical treatment for NSCLC patients with this disease stage $(8,13)$. To date, many studies have been conducted to explore the most suitable surgical options in the general population. Some researchers have reported that while sublobectomy does not yield inferior OS to lobectomy in patients with stage IA NSCLC, the recurrence rate is relatively high (19). Similar to the conclusion drawn by Gu et al., the results of this study suggest that for younger patients, the prognosis of sublobectomy is no worse than that of lobectomy (20). Moreover, previous studies have shown that sublobectomy compared to lobectomy can preserve more lung function 
Table 2 Univariable analysis of overall and disease-free survival in 191 patients with pIA NSCLC

\begin{tabular}{|c|c|c|c|c|}
\hline Characteristic & \multicolumn{2}{|c|}{ DFS } & \multicolumn{2}{|c|}{ OS } \\
\hline Sex & 0.000 & 0.989 & 0.440 & 0.507 \\
\hline Age (y) & 2.529 & 0.112 & 7.484 & 0.006 \\
\hline Tumor marker level & 1.966 & 0.374 & 1.210 & 0.546 \\
\hline Surgical technique & 0.408 & 0.523 & 0.174 & 0.677 \\
\hline Operative procedure & 0.004 & 0.951 & 0.747 & 0.387 \\
\hline Predominant subtype & 3.580 & 0.058 & 2.695 & 0.101 \\
\hline Tumor location & 1.920 & 0.750 & 1.143 & 0.887 \\
\hline
\end{tabular}

NSCLC, non-small cell lung cancer; LND, lymph node dissection; OS, overall survival; DFS, disease-free survival.

Table 3 Multivariable Cox regression analysis of overall and disease-free survival in 191 patients with pIA NSCLC

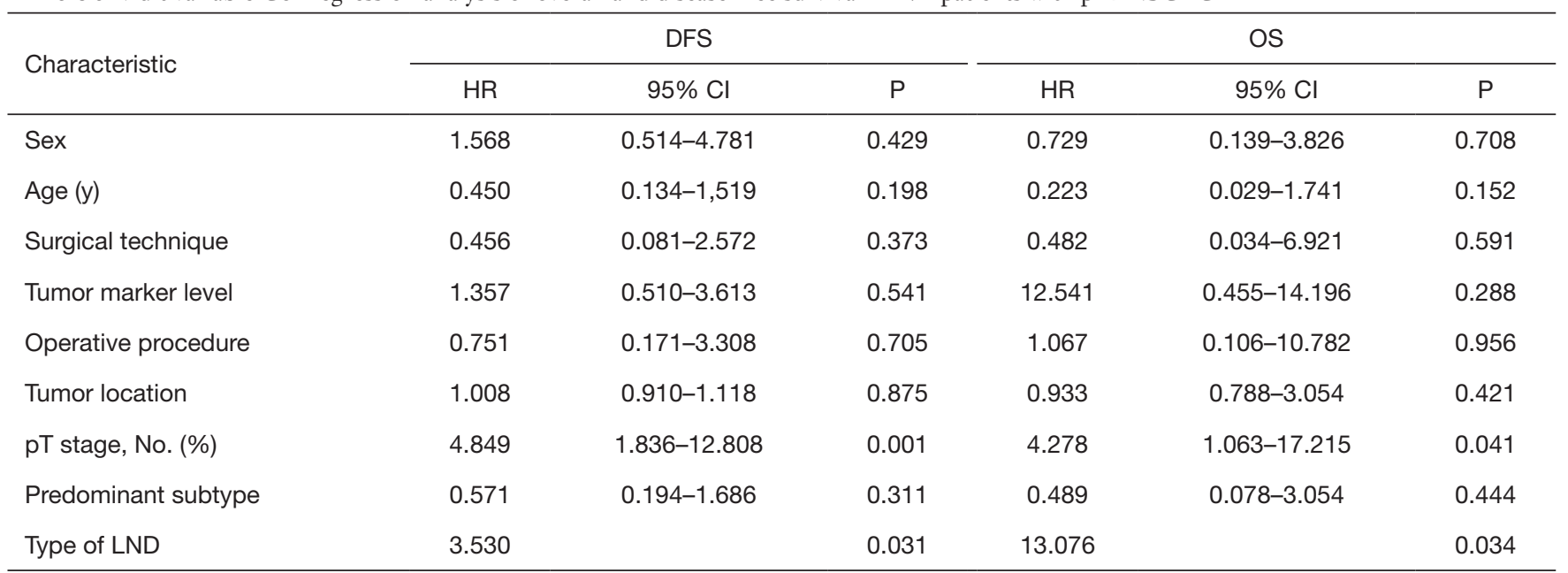

NSCLC, non-small cell lung cancer; LND, lymph node dissection; OS, overall survival; DFS, disease-free survival; HR, hazard ratio.

and lead to fewer complications, which is particularly important to preserving the quality of life of young patients after surgery. Therefore, our results suggest that sublobectomy may be a better choice than lobectomy for younger patients with stage IA NSCLC.

A number of studies have explored the application of LND in thoracic surgeries. A large prospective study showed no difference between SLND, sampling, and SLND in the prognosis of early NSCLC (21). Furthermore, Gonfiotti et al. found that postoperative complications incidence among patients who underwent SLND were no more significant than those among non-dissection patients (22). However, numerous studies have shown that SLND leads to lower rates of local recurrence in the general population (23-25), and another study found that SLND had survival benefit for patients with early NSCLC in teaching hospitals (but not in non-teaching hospitals) (26). Mokhles et al. reported that SLND was associated with more complications than sampling or no dissection (27). Although the results of studies so far have been inconsistent, the current NCCN guidelines recommend treatment according to the $\mathrm{pN}$ stage (13). Accurate lymph node staging is of guiding significance for postoperative adjuvant therapy $(28,29)$. Additionally, several recent studies have suggested that the higher the number of lymph nodes removed, the better the prognosis (30-32). 
A conclusion has yet to be reached on the best type of LND for the general NSCLC population, not to mention young patients. The data from this age-specific study suggested that among young patients with stage IA, those who underwent SLND had a better prognosis than those who did not. This observation differs from Gu's conclusion that the effect of SLND on prognosis is consistent with that of sampling (20). The underlying reason for this inconsistency may be that the 2 studies used different patient populations, different definitions of SLND, and different age cut-offs for young people.

During the collection of the data in this study, $\mathrm{pN} 0$ patients had been strictly screened to exclude the influence caused by $\mathrm{N}$ stage on prognosis. Other than $\mathrm{N}$ stage, we considered a number of possible reasons for the difference in prognosis between SLND and non-SLND patients. First, in undissected lymph nodes, metastases may potentially occur, resulting in a poor prognosis. Second, SLND may remove micrometastases, although this may not be shown by positive pathological results. Third, SLND may prevent the occurrence of skip metastasis. These possibilities and other potential causes need to be explored with more studies and larger samples; however, whatever the reasons, our findings suggest the importance of intraoperative SLND.

Current studies on young patients with NSCLC show that the incidence is higher in women than in men and that the most common histologic type is adenocarcinoma $(6,33)$. Our study also showed that young women were more than twice as likely as men to have NSCLC. Furthermore, our study also showed that the effect of circulating tumor markers on prognosis was not significant in young patients, nor did the prognosis differ significantly according to the pathological subtype. At the same time, the study confirmed that $\mathrm{T}$ stage has an important effect on the prognosis of young patients, while the prognosis of VATS is no worse than that of thoracotomy.

\section{Limitations}

Our study has several limitations that should be discussed. First, the existence of selection bias cannot be avoided in single-center and retrospective studies. Also, due to the special population and the inclusion criteria, the sample size of this study was extremely small; therefore, our results need to be verified in a study with a larger sample size. Due to the limitations of medical record data, we did not collect data in enough multiple dimensions, which may have limited the analysis of patient survival.
Furthermore, our results reported a prognostic advantage of SLND over no SLND, and the multivariate Cox survival analysis showed that the prognosis with sublobectomy was no worse than that with lobectomy. However, the sample size was not sufficient for subgroup analysis to confirm survival differences between lobectomy and sublobectomy in patients with SLND. Therefore, we still cannot recommend sublobectomy with LND as the optimal surgical procedure for young stage IA NSCLC patients aged $\leq 40$ years.

\section{Conclusions}

Among young (aged $\leq 40$ years) stage IA NSCLC patients with pathological invasive adenocarcinoma, SLND was associated with a better prognosis than no SLND, which suggests that thorough SLND should be performed in young patients with invasive adenocarcinoma indicated by intraoperative frozen or preoperative puncture biopsy pathology. Given the nature of this single-center retrospective study, further prospective multicenter studies are needed to confirm our conclusions.

\section{Acknowledgments}

Funding: This research was supported by the National Natural Science Foundation of China (No. 81871497).

\section{Footnote}

Reporting Checklist: The authors have completed the STROBE reporting checklist. Available at http://dx.doi. org/10.21037/jtd-21-190

Data Sharing Statement: Available at http://dx.doi. org/10.21037/jtd-21-190

Conflicts of Interest: All authors have completed the ICMJE uniform disclosure form (available at http://dx.doi. org/10.21037/jtd-21-190). The authors have no conflicts of interest to declare.

Ethical Statement: The authors are accountable for all aspects of the work in ensuring that questions related to the accuracy or integrity of any part of the work are appropriately investigated and resolved. The study was conducted in accordance with the Declaration of Helsinki (as revised in 2013). The study was approved by the institutional ethics board of Shanghai Chest Hospital [No. 
$\mathrm{KS}(\mathrm{Y}) 1744$ ] and individual consent for this retrospective analysis was waived.

Open Access Statement: This is an Open Access article distributed in accordance with the Creative Commons Attribution-NonCommercial-NoDerivs 4.0 International License (CC BY-NC-ND 4.0), which permits the noncommercial replication and distribution of the article with the strict proviso that no changes or edits are made and the original work is properly cited (including links to both the formal publication through the relevant DOI and the license). See: https://creativecommons.org/licenses/by-nc-nd/4.0/.

\section{References}

1. Siegel RL, Miller KD, Jemal A. Cancer statistics, 2020. CA Cancer J Clin 2020;70:7-30.

2. Moyer VA. Screening for lung cancer: U.S. Preventive Services Task Force recommendation statement. Ann Intern Med 2014;160:330-8.

3. Field JK, Smith RA, Aberle DR, et al. International Association for the Study of Lung Cancer Computed Tomography Screening Workshop 2011 report. J Thorac Oncol 2012;7:10-9.

4. Fidler MM, Gupta S, Soerjomataram I, et al. Cancer incidence and mortality among young adults aged 20-39 years worldwide in 2012: a population-based study. Lancet Oncol 2017;18:1579-89.

5. Sacher AG, Dahlberg SE, Heng J, et al. Association Between Younger Age and Targetable Genomic Alterations and Prognosis in Non-Small-Cell Lung Cancer. JAMA Oncol 2016;2:313-20.

6. Garrana SH, Dagogo-Jack I, Cobb R, et al. Clinical and Imaging Features of Non-Small-Cell Lung Cancer in Young Patients. Clin Lung Cancer 2021;22:23-31.

7. Wright G, Manser RL, Byrnes G, et al. Surgery for nonsmall cell lung cancer: systematic review and meta-analysis of randomised controlled trials. Thorax 2006;61:597-603.

8. Lang-Lazdunski L. Surgery for nonsmall cell lung cancer. Eur Respir Rev 2013;22:382-404.

9. Choe G, Schipper P. Quality of Lymph Node Assessment and Survival Among Patients With Non-Small Cell Lung Cancer. JAMA Oncol 2018;4:1-2.

10. Darling GE. Current status of mediastinal lymph node dissection versus sampling in non-small cell lung cancer. Thorac Surg Clin 2013;23:349-56.

11. Smeltzer MP, Faris NR, Ray MA, et al. Association of Pathologic Nodal Staging Quality With Survival Among
Patients With Non-Small Cell Lung Cancer After Resection With Curative Intent. JAMA Oncol 2018;4:807.

12. Darling GE, Allen MS, Decker PA, et al. Randomized trial of mediastinal lymph node sampling versus complete lymphadenectomy during pulmonary resection in the patient with $\mathrm{N} 0$ or N1 (less than hilar) non-small cell carcinoma: results of the American College of Surgery Oncology Group Z0030 Trial. J Thorac Cardiovasc Surg 2011;141:662-70.

13. National Comprehensive Cancer Network. NCCN guidelines for treatment of cancer by site: non-small cell lung cancer. Available online: https://www.ncen.org/ professionals/physician_gls/default.aspx\#site; 2020.

14. Detterbeck FC, Boffa DJ, Kim AW, et al. The Eighth Edition Lung Cancer Stage Classification. Chest 2017;151:193-203.

15. Travis WD, Brambilla E, Noguchi $M$, et al. International association for the study of lung cancer/american thoracic society/european respiratory society international multidisciplinary classification of lung adenocarcinoma. J Thorac Oncol 2011;6:244-85.

16. Sica G, Yoshizawa A, Sima CS, et al. A grading system of lung adenocarcinomas based on histologic pattern is predictive of disease recurrence in stage I tumors. Am J Surg Pathol 2010;34:1155-62.

17. Yoshizawa A, Motoi N, Riely GJ, et al. Impact of proposed IASLC/ATS/ERS classification of lung adenocarcinoma: prognostic subgroups and implications for further revision of staging based on analysis of 514 stage I cases. Mod Pathol 2011;24:653-64.

18. Lardinois D, De Leyn P, Van Schil P, et al. ESTS guidelines for intraoperative lymph node staging in non-small cell lung cancer. Eur J Cardiothorac Surg 2006;30:787-92.

19. Ginsberg RJ, Rubinstein LV. Randomized trial of lobectomy versus limited resection for T1 N0 non-small cell lung cancer. Lung Cancer Study Group. Ann Thorac Surg 1995;60:615-22; discussion 622-3.

20. Gu C, Wang R, Pan X, et al. Sublobar resection versus lobectomy in patients aged $</=35$ years with stage IA nonsmall cell lung cancer: a SEER database analysis. J Cancer Res Clin Oncol 2017;143:2375-82.

21. Allen MS, Darling GE, Pechet TT, et al. Morbidity and mortality of major pulmonary resections in patients with early-stage lung cancer: initial results of the randomized, prospective ACOSOG Z0030 trial. Ann Thorac Surg 2006;81:1013-9; discussion 1019-20. 
22. Gonfiotti A, Bertani A, Nosotti M, et al. Safety of lymphadenectomy during video-assisted thoracic surgery lobectomy: analysis from a national database. Eur J Cardiothorac Surg 2018;54:664-70.

23. Doddoli C, Aragon A, Barlesi F, et al. Does the extent of lymph node dissection influence outcome in patients with stage I non-small-cell lung cancer? Eur J Cardiothorac Surg 2005;27:680-5.

24. Lardinois D, Suter H, Hakki H, et al. Morbidity, survival, and site of recurrence after mediastinal lymph-node dissection versus systematic sampling after complete resection for non-small cell lung cancer. Ann Thorac Surg 2005;80:268-74; discussion 274-5.

25. Massard G, Ducrocq X, Kochetkova EA, et al. Sampling or node dissection for intraoperative staging of lung cancer: a multicentric cross-sectional study. Eur J Cardiothorac Surg 2006;30:164-7.

26. Ray MA, Smeltzer MP, Faris NR, et al. Survival After Mediastinal Node Dissection, Systematic Sampling, or Neither for Early Stage NSCLC. J Thorac Oncol 2020;15:1670-81.

27. Mokhles S, Macbeth F, Treasure T, et al. Systematic lymphadenectomy versus sampling of ipsilateral mediastinal lymph-nodes during lobectomy for nonsmall-cell lung cancer: a systematic review of randomized trials and a meta-analysis. Eur J Cardiothorac Surg 2017;51:1149-56.

28. Asamura H, Chansky K, Crowley J, et al. The

Cite this article as: Guo ZY, Ren JH, Xu YY, Liu RJ, Tao H, Huang J, Tan Q. The significance of systematic lymph node dissection in surgery for early-stage non-small cell lung cancer patients aged $\leq 40$ years. J Thorac Dis 2021;13(2):1196-1204. doi: $10.21037 /$ jtd-21-190
International Association for the Study of Lung Cancer Lung Cancer Staging Project: Proposals for the Revision of the N Descriptors in the Forthcoming 8th Edition of the TNM Classification for Lung Cancer. J Thorac Oncol 2015;10:1675-84.

29. Früh M, Rolland E, Pignon JP, et al. Pooled analysis of the effect of age on adjuvant cisplatin-based chemotherapy for completely resected non-small-cell lung cancer. J Clin Oncol 2008;26:3573-81.

30. Xu F, Qi L, Yue D, et al. The effect of the extent of lymph node dissection for stage IA non-small-cell lung cancer on patient disease-free survival. Clin Lung Cancer 2013;14:181-7.

31. Yendamuri S, Dhillon SS, Groman A, et al. Effect of the number of lymph nodes examined on the survival of patients with stage I non-small cell lung cancer who undergo sublobar resection. J Thorac Cardiovasc Surg 2018;156:394-402.

32. Samayoa AX, Pezzi TA, Pezzi CM, et al. Rationale for a Minimum Number of Lymph Nodes Removed with Non-Small Cell Lung Cancer Resection: Correlating the Number of Nodes Removed with Survival in 98,970 Patients. Ann Surg Oncol 2016;23:1005-11.

33. Jemal A, Miller KD, Ma J, et al. Higher Lung Cancer Incidence in Young Women Than Young Men in the United States. N Engl J Med 2018;378:1999-2009.

(Language Editor: J. Reynolds) 